\title{
Tissue Microarray Is a Reliable Tool for the Evaluation of HER2 Amplification in Breast Cancer
}

\author{
DANIELA FURRER ${ }^{1,2,3}$, SIMON JACOB $^{4,5,6}$, CHANTAL CARON ${ }^{4,5}$, \\ FRANÇOIS SANSCHAGRIN ${ }^{2,4}$, LOUISE PROVENCHER ${ }^{2,4,7}$ and CAROLINE DIORIO ${ }^{1,2,3,4}$ \\ ${ }^{1}$ Cancer Research Centre at Laval University, ${ }^{2}$ Oncology Axis, CHU of Quebec Research Center, and \\ Departments of ${ }^{3}$ Social and Preventive Medicine, ${ }^{6}$ Molecular Biology, Medical Biochemistry and Pathology, and \\ ${ }^{7}$ Surgery, Faculty of Medicine, Laval University, Quebec City, QC, Canada; \\ ${ }^{4}$ Deschênes-Fabia Center for Breast Diseases and \\ ${ }^{5}$ Pathology Service, Saint-Sacrement Hospital, Quebec City, QC, Canada
}

\begin{abstract}
Aim: We examined an economical method for evaluating the amplification of the human epidermal growth factor receptor 2 (HER2) gene in breast cancer specimens. Materials and Methods: We compared HER2 amplification determined by fluorescence in situ hybridization (FISH) on whole-tissue (WT) blocks used for diagnostic and on tissue microarray (TMA) sections for a cohort of 521 consecutive patients with breast cancer. In a subset of 116 patients, we examined HER 2 concordance from the WT section and a TMA section from a randomly chosen additional block ( $a$ proxy of the core biopsy). Results: Overall concordance for HER2 amplification between WT and TMA sections was $98.2 \%$, and between sections from WT and from the additional block was $99.0 \%$. Conclusion: The high concordance rates support the use of TMA for the evaluation of HER2 amplification in breast cancer and suggest that FISH can be used to assess HER2 using core biopsies.
\end{abstract}

The human epidermal growth factor receptor 2 (HER2) gene is located on chromosome 17 and encodes a transmembrane tyrosine kinase receptor protein (1). HER2 gene amplification and receptor overexpression, which occur in 15 to $20 \%$ of patients with breast cancer, are important

This article is freely accessible online.

Correspondence to: Associate Professor Caroline Diorio, Ph.D., Département de médecine sociale et préventive , Université Laval, Axe oncologie, Centre de recherche du CHU de Québec, Centre des maladies du sein Deschênes-Fabia, Hôpital du Saint-Sacrement, 1050, chemin Ste-Foy, local J0-16, Québec (Qc) G1S 4L8, Canada. Tel: +1 4186827511, ext. 84726, Fax: +1 4186827949, e-mail: caroline.diorio@crchudequebec.ulaval.ca

Key Words: Breast cancer, trastuzumab, TMA, ASCO/CAP guidelines, HER2 status, FISH. markers for poor prognosis, including a more aggressive disease and a shorter survival (2). Moreover, HER2-positive status is considered a predictive marker of response to antiHER2 therapies (3). Given its prognostic, predictive and therefore therapeutic implications, accurate diagnostic assessment of HER2 is essential for reliable identification of patients eligible for HER2-targeted drugs.

Currently, there are several Food and Drug (FDA)approved methods for evaluating HER2 status, including immunohistochemical (IHC) evaluation of HER2 protein expression and assessment of HER2 gene amplification by in situ hybridization (ISH), most commonly fluorescent ISH (FISH) $(4,5)$. Since both IHC and FISH present advantages and disadvantages, there is still no consensus on which method is superior for assessing HER2 status in breast cancer specimens (6). In 2013, the American Society of Clinical Oncology/College of American Pathologists (ASCO/CAP) updated the guidelines to clarify the recommendations for HER2 testing in breast cancer specimens published in 2007 (4). In addition to report new scoring criteria, the updated guidelines recommend performing an initial test of a core biopsy. If test results are equivocal, reflex testing on tumor specimen section with an alternative assay should be carried out. In addition, repeat testing should be performed if there is an apparent histopathological discordance with the test result. The 2007 ASCO/CAP guidelines recommended to perform HER2 testing on resection specimens and to retest when results were equivocal (5). Although FISH is a reliable method for evaluation of HER2 status in breast cancer for diagnostic purposes or in the framework of quality control, it is a very expensive technique (7).

Tissue microarray (TMA) allows for simultaneous molecular analysis of large numbers of samples by means of arranging tissue cores from multiple specimens into an empty paraffin block $(8,9)$. A low degree of representativity 
compared to whole-tissue sections, however, represents the major limitation of this technology. The purpose of this project was to determine the most reliable and economical method for evaluating HER2 status in breast cancer specimens. In a cohort of 521 consecutive patients with breast cancer, we aimed to evaluate if FISH analysis performed on TMA section provides comparable results to those obtained using whole-tissue sections used for diagnostic purposes (one section per slide). Furthermore, we wanted to assess whether FISH analysis carried out on a randomly chosen additional block (a proxy of a random core biopsy) yielded similar results. In a subset of 116 breast cancer specimens, we aimed to analyze the concordance between HER2 gene amplification status obtained from the same whole-tissue section used for diagnostics and that obtained from the randomly chosen additional block using TMA.

\section{Materials and Methods}

Specimen collection and patient population. Specimens were obtained from mastectomies and segmental resections that were performed at the Centre des Maladies du Sein Deschênes-Fabia at the Saint-Sacrement Hospital in Québec, Québec, Canada, between February 2011 and April 2012. Samples were fixed with $10 \%$ neutral buffered formalin, embedded in paraffin, cut into 4$\mu \mathrm{m}$ tissue sections, stained with hematoxylin and eosin (H\&E), and used for routine pathological evaluation. The study population consisted of 554 consecutive cases of invasive breast carcinoma, with a tumor size on histological slides of at least $1 \mathrm{~cm}$, which did not receive chemotherapy prior to surgery. All eligible women provided their written informed consent for use of their tissue. Ethical approval of the study was obtained in 2010 from the Research Ethics Committee of the Centre de Recherche du CHU de Québec (\#DR-002-1286).

Tissue microarray construction and processing. TMAs were constructed as previously described (10). For the 554 consecutive breast cancer specimens, the most representative tissue block from each case was chosen by the pathologist for HER2 evaluation by IHC and FISH. Subsequently, two tumoral regions showing the strongest IHC staining were delineated on the IHC slide by the pathologist. Within each delimited tumor zone, pathologists indicated where two $0.6 \mathrm{~mm}$ tissue cylinders were to be punched. The four tissue cylinders were punched using a manual arraying instrument (Beecher Instruments, Silver Spring, MD, USA) and were inserted into empty recipient paraffin blocks. We call these TMA blocks 'diagnostic TMA'. Among the 554 cases present on the diagnostic TMA, we identified 279 cases that had at least two additional paraffin blocks presenting the same histological type as the paraffin block that was used for the construction of the diagnostic TMA and having enough tumor tissue to extract four tissue cylinders. Among these 279 cases, 100 cases were randomly chosen. For each of these randomly selected cases, one paraffin block was randomly chosen among all eligible paraffin blocks. Suitable blocks were identified using $\mathrm{H} \& \mathrm{E}$ section and two tumoral regions were identified without previous IHC staining on the H\&E section by two trained technologists and verified by a pathologist. Four $0.6 \mathrm{~mm}$ tissue cylinders were then punched from these regions. Moreover, we performed an oversampling of HER2-positive cases: 16 cases that were scored as HER2-positive on diagnostic TMA section but that had not been selected at random were added to the 100 cases. Therefore, a total of 116 cases were inserted into empty recipient paraffin blocks. We call these TMA blocks 'random TMA' in order to differentiate it from the diagnostic TMA. On each array block, breast cancer cell lines (MCF-7, MDA-231 and SKBR-3) were included in duplicate and served as negative and positive controls. Four-micrometer TMA sections were processed by FISH following the same protocol as for the whole-tissue section used for diagnostics. One section from each TMA block was stained with H\&E for reference histology.

Fluorescence in situ hybridization. HER2 gene copy number was evaluated using the FDA-approved PathVysion ${ }^{\text {TM }}$ HER2 DNA Probe kit (Abbott Molecular, Des Plaines, IL, USA/Inter Medico, Markham, Canada). Fluorescent signals were analyzed with an epifluorescence microscope Axio Imager M1 (Zeiss, Göttingen, Germany), equipped with a triple-band filter [4',6-diamidino-2-phenylindole (DAPI)/green/orange]. Automated analysis of fluorescence signals was performed using the FDA-approved MetaSystems ${ }^{\mathrm{TM}}$ image analysis system, equipped with Metafer software with extended focus/tile sampling (MetaSystems, Altussheim, Germany) (11). After selection of 5 to 10 non-overlapping fields of infiltrating carcinoma, field images were automatically captured and analyzed by the software. HER2 gene amplification was reported according to the 2007 and 2013 ASCO/CAP guidelines for the evaluation of HER2 status in breast cancer specimens (Table I) $(4,5)$. For equivocal cases, manual counting was performed from at least 60 nonoverlapping tumor cells from two distinct tumor areas. Equivocal cases were counted by two independent technologists and reviewed by the pathologist of the study. In addition, manual counting was performed in 40 nonoverlapping tumor cells when the average HER2 copy number per tile was $\geq 4.0$ and $\leq 6.0$ at the automated image analysis. Normal breast epithelial cells, lymphocytes and fibroblasts were used as internal control. Slides were analyzed by trained technologists, and all results were validated by breast pathologists with experience in FISH interpretation.

HER2 evaluation on TMA. A core was considered unsatisfactory for analysis if it was absent, it contained no tumor tissue, or if tumor tissue occupied less than $10 \%$ of the total core area. Fluorescent signals on TMA slides were evaluated in the same way as for the whole-tissue section. Fluorescent signals were first analyzed using an FDA-approved automated image analysis system (MetaSystems) (11). Slides were scanned at low magnification $(\times 5)$ to generate a position list corresponding to each core in order to link the core location to subsequent high-resolution $(x 40)$ FISH images. Automated image analysis was followed by manual counting or visual verification using the same criteria as for whole-tissue sections. Each informative core was scored separately in a blind fashion. Average FISH results of informative cores were considered. All results were validated by breast pathologists. HER2 FISH results were reported using the same scoring guidelines as for whole-tissue section analysis $(4,5)$.

Statistical analysis. Only cases with at least one informative core were included in the analysis. FISH results on both whole-tissue and 
Table I. Interpretation criteria for fluorescence in situ hybridization according to the 2007 (5) and the 2013 (4) American Society of Clinical Oncology/College of American Pathologists scoring systems.

\begin{tabular}{lcc}
\hline Scoring system & Result category & Interpretation criteria \\
\hline 2007 & Non-amplified & $H E R 2 / C E P 17$ ratio $<1.8$ \\
& Equivocal & $H E R 2 / C E P 17$ ratio $1.8-2.2$ \\
& Amplified & $H E R 2 / C E P 17$ ratio $>2.2$ \\
2013 & Non-amplified & Average $H E R 2$ gene copy number $<4$ signals/nucleus or $H E R 2 / C E P 17$ ratio of \\
& Equivocal & $<2.0$ with an average $H E R 2$ gene copy number $<4$ signals $/$ nucleus \\
& Average $H E R 2$ gene copy number $\geq 4$ and $<6$ signals $/$ nucleus or a ratio $<2.0$ \\
& Amplified & with an average $H E R 2$ gene copy number $\geq 4$ and $<6$ signals $/$ nucleus \\
& an average $H E R 2$ gene copy number $\geq 6$ signals $/$ nucleus or a ratio $\geq 2.0$ \\
\hline
\end{tabular}

HER2/CEP17: Human epidermal growth factor receptor 2/chromosome 17 centromere.

Table II. Concordance of human epidermal growth factor receptor 2 (HER2) gene amplification status between fluorescence in situ hybridization performed on whole tissue sections (reference method) and on diagnostic tissue microarray (TMA) sections according to the 2013 American Society of Clinical Oncology/College of American Pathologists scoring system (4).

\begin{tabular}{lcccc}
\hline & \multicolumn{2}{c}{ Whole-tissue section (reference), $\mathrm{n}$} & \\
\cline { 2 - 4 } $\begin{array}{l}\text { Diagnostic TMA } \\
\text { section }\end{array}$ & Non-amplified & Equivocal & Amplified & Total \\
\hline Non-amplified, $\mathrm{n}$ & 424 & 19 & 3 & 446 \\
Equivocal, n & 5 & 5 & 0 & 10 \\
$\begin{array}{l}\text { Amplified, } \mathrm{n} \\
\text { Total }\end{array}$ & 1 & 0 & 64 & 65 \\
$\begin{array}{l}\text { Overall agreement } \\
\text { Positive agreement } \\
\text { (sensitivity) }\end{array}$ & 430 & 24 & 67 & 521 \\
$\begin{array}{l}\text { Negative agreement } \\
\text { (specificity) }\end{array}$ & & & & $98.2 \%$ \\
$k$ Value & & & & \\
\hline
\end{tabular}

*When equivocal cases were excluded: $k$ value $=0.96$.

TMA sections were available for 521 cases out of the 554 total cases $(94.0 \%)$. FISH results on both whole-tissue and random TMA sections were available for 103 cases out of the 116 selected cases $(88.8 \%)$. In order to evaluate the agreement between FISH results obtained by the different methods (whole-tissue section vs. diagnostic TMA section and whole-tissue section $v s$. random TMA section), positive, negative and overall concordance were calculated. Positive concordance (sensitivity) was calculated as the number of samples positive for both methods divided by the number of samples positive by the reference FISH assay. Negative agreement (specificity) was calculated similarly. Overall concordance was defined as the combination of sensitivity and specificity, as recommended by the ASCO/CAP guidelines $(4,5)$. In addition, the level of concordance was measured using Cohen's kappa test. All analyses were performed using SAS software (version 9.1.3; SAS Institute Inc., Cary, NC, USA).
Table III. Concordance of human epidermal growth factor receptor 2 (HER2) gene amplification status between fluorescence in situ hybridization performed on whole tissue sections (reference method) and on diagnostic tissue microarray (TMA) sections according to the 2007 American Society of Clinical Oncology/College of American Pathologists scoring system (5).

\begin{tabular}{lcccc}
\hline \multirow{2}{*}{$\begin{array}{l}\text { Diagnostic TMA } \\
\text { section }\end{array}$} & \multicolumn{3}{c}{ Whole-tissue section (reference) } & \\
\cline { 2 - 4 } & Non-amplified & Equivocal & Amplified & Total \\
\hline Non-amplified & 451 & 3 & 0 & 454 \\
Equivocal & 0 & 2 & 1 & 3 \\
Amplified & 0 & 4 & 60 & 64 \\
Total & 451 & 9 & 61 & 521 \\
$\begin{array}{l}\text { Overall agreement } \\
\text { Positive agreement }\end{array}$ & & & & $99.8 \%$ \\
(sensitivity) & & & & $98.4 \%$ \\
$\begin{array}{l}\text { Negative agreement } \\
\text { (specificity) }\end{array}$ & & & & $100.0 \%$ \\
$k$ Value & & & $0.93 *$ \\
\hline
\end{tabular}

*When equivocal cases were excluded: $k$ value $=1.00$.

\section{Results}

Concordance of the FISH HER2 results between wholetissue and diagnostic TMA sections are summarized in Table II. Using the 2013 ASCO/CAP scoring system, the overall agreement was $98.2 \%$ (kappa value $=0.81$ ). The positive agreement and the negative agreements were $95.5 \%$, and $98.6 \%$, respectively. The one case that was evaluated as nonamplified on the whole-tissue section but amplified on diagnostic TMA section showed borderline amplification (mean HER2/CEP17 ratio 2.27 on diagnostic TMA section and HER2/CEP17 ratio of 1.80 on whole-tissue section). Similarly, the three cases that were scored as amplified on whole-tissue sections but non-amplified on diagnostic TMA 
Table IV. Concordance of human epidermal growth factor receptor 2 (HER2) gene amplification status between fluorescence in situ hybridization performed on whole tissue sections (reference method) and on diagnostic tissue microarray (TMA) sections according to the number of informative cores using the 2007 American Society of Clinical Oncology/College of American Pathologists scoring system (n=521) (5).

\begin{tabular}{|c|c|c|c|c|c|c|c|}
\hline \multirow[t]{2}{*}{ Number of assessable cores } & \multirow[t]{2}{*}{ Number of cases } & \multicolumn{2}{|c|}{ Overall agreement } & \multicolumn{2}{|c|}{ Positive agreement } & \multicolumn{2}{|c|}{ Negative agreement } \\
\hline & & $\mathrm{n} / \mathrm{N}$ & $\%$ & $\mathrm{n} / \mathrm{N}$ & $\%$ & $\mathrm{n} / \mathrm{N}$ & $\%$ \\
\hline 1 or 2 & 162 & $156 / 157$ & 99.4 & $21 / 22$ & 95.4 & $135 / 135$ & 100.0 \\
\hline 3 or 4 & 359 & $355 / 355$ & 100.0 & $39 / 39$ & 100.0 & $316 / 316$ & 100.0 \\
\hline
\end{tabular}

$\mathrm{n} / \mathrm{N}$ : Number of cases on TMA section/number of cases on whole-tissue section.

sections showed borderline amplification (HER2/CEP17 ratios ranging from 2.11 to 2.31 on whole-tissue sections, mean HER2/CEP17 ratios ranging from 1.37 to 1.85 on diagnostic TMA sections).

We also assessed the concordance rates between HER2 gene amplification status determined by FISH on wholetissue sections and on TMA sections according to the number of informative cores per case (one or two vs. three or four cores). The overall, positive, and negative agreements for cases with one or two informative cores were $98.6 \%, 95.8 \%$ and $99.2 \%$, respectively. For cases with three or four evaluable cores, the overall, positive and negative agreements were $97.9 \%, 95.3 \%$ and $98.4 \%$, respectively.

Similar concordance rates between the two methods were observed when the 2007 ASCO/CAP guidelines were applied (Tables III and IV).

Concordance of HER2 status determined by FISH on whole-tissue sections and random TMA sections is summarized in Table V. The overall agreement was $99.0 \%$ (kappa value $=0.94$ ). The positive agreement and the negative agreements were $97.3 \%$, and $100.0 \%$, respectively. The case that was considered amplified on the whole-tissue section and equivocal on random TMA section had a HER2/CEP17 ratio of 2.50 on the whole-tissue section, while on random TMA section it had a mean HER2/CEP17 ratio of 1.67 and an average $H E R 2$ gene copy number of 4.53 .

\section{Discussion}

We observed a high concordance rate between the HER2 gene amplification status assessed by FISH on whole-tissue sections and on diagnostic TMA section, independently form the ASCO/CAP guideline used for the classification of cases. Using the 2013 ASCO/CAP scoring criteria, 98.2\% of cases were correctly classified, whereas overall concordance was $99.8 \%$ when the oldest scoring criteria were applied. Similar studies performed on breast cancer specimens reported concordance rates ranging from $91 \%$ to $97 \%$ between the HER 2 gene amplification status obtained by FISH on whole-
Table V. Concordance of human epidermal growth factor receptor 2 (HER2) status determined by fluorescence in situ hybridization on whole-tissue section (reference method) and on random TMA section according to the 2013 ASCO/CAP scoring system (4).

\begin{tabular}{|c|c|c|c|c|}
\hline \multirow{2}{*}{$\begin{array}{l}\text { Random } \\
\text { TMA section }\end{array}$} & \multicolumn{3}{|c|}{ Whole-tissue section (reference) } & \multirow[b]{2}{*}{ Total } \\
\hline & Non-amplified & Equivocal & Amplified & \\
\hline Non-amplified & 63 & 2 & 0 & 65 \\
\hline Equivocal & 0 & 1 & 1 & 2 \\
\hline Amplified & 0 & 0 & 36 & 36 \\
\hline Total & 63 & 3 & 37 & 103 \\
\hline Overall agreement & & & & $99.0 \%$ \\
\hline $\begin{array}{l}\text { Positive agreement } \\
\text { (sensitivity) }\end{array}$ & & & & $97.3 \%$ \\
\hline $\begin{array}{l}\text { Negative agreement } \\
\text { (specificity) }\end{array}$ & & & & $100.0 \%$ \\
\hline$k$ Value & & & & $0.94 *$ \\
\hline
\end{tabular}

*When equivocal cases were excluded: $k$ value $=1.00$.

tissue sections and TMA sections using 2007 ASCO/CAP scoring criteria (12-15). In our hands, no case considered amplified on whole-tissue section was evaluated as nonamplified on diagnostic TMA section, when HER2 gene amplification status was scored according to the 2007 ASCO/CAP scoring guidelines $(4.5 \%$ using the newest scoring guidelines). Gancberg and collaborators reported similar results (12), whereas another study observed $13 \%$ of non-amplified cases on TMA section among those considered amplified on whole-tissue section (15).

In analogy to others $(14,16,17)$, we noticed that the overall agreement rate between the two methods was higher with three- or four-core analysis compared to one- or twocore analysis when 2007 ASCO/CAP scoring criteria were used (100.0\% vs. 99.4\%). However, when the 2013 ASCO/CAP guidelines were used, we obtained opposite results (three or four cores: $98.0 \%$, one or two cores: $98.6 \%$ ). 
The overall concordance between $H E R 2$ gene amplification status between the two methods was also high when HER2 status determined on TMA section was considered the reference method $(95.6 \%$ using the newest guidelines and 98.6\% using the 2007 ASCO/CAP scoring guidelines), further confirming the reliability of this method in the determination of HER2 gene amplification in breast cancer specimens.

The purpose of our project was also to compare HER2 gene amplification status obtained from the same whole-tissue section used for diagnostics to those obtained from the randomly chosen additional block using TMA. The updated ASCO/CAP guidelines recommend performing an initial test (IHC or ISH) in core biopsy and to retest specimens using an alternative assay when results are equivocal. Since FISH was not routinely performed in core biopsy for the 554 consecutive breast cancer specimens, we performed FISH for 116 selected breast cancer specimens on an additional paraffin block, randomly chosen among all paraffin blocks of the same specimen that presented the same histological type as the routine diagnostic paraffin block, i.e. the paraffin block that was used to make the diagnosis. Since the additional block and the additional cores were randomly chosen, we consider this block a proxy of the core biopsy performed by the radiologist under ultrasound examination. We observed an excellent overall concordance (99.0\%, kappa value of 0.94 ) between the HER2 gene amplification status observed on whole-tissue and on random TMA sections. These results highlight that reliable $H E R 2$ gene amplification status can be achieved even when the tumor area is randomly chosen.

Similar studies have analyzed concordance of HER2 status (determined on whole-tissue section) between different blocks from different tumor foci $(18,19)$. Compared to our results, two studies have reported slightly lower concordance rates in HER2 gene amplification determined on different blocks, ranging from $90.3 \%$ to $94 \%$. These studies, however, analyzed their results using the 2007 ASCO/CAP guidelines (19) or other criteria for HER2 gene amplification (18). Analogous studies that analyzed the concordance between HER 2 gene amplification determined on the needle core biopsy and subsequent excisional biopsy (whole-tissue section) of the same tumor observed comparatively to our study lower agreement rates ranging between $86 \%$ and $92 \%(20,21)$.

TMA technology has several advantages over the traditional method. Variability between batches is considerably reduced, since specimens can be simultaneously processed using identical conditions $(8,9)$. Furthermore, the TMA technique significantly reduces the reagents and technical time required for staining $(22,23)$. This is particularly attractive for expensive and time-consuming techniques such as FISH. The amount of tissue needed is also reduced (23).

Although TMA represents a useful tool for rapid and efficient examination of large numbers of tumor tissues, this technique presents some weaknesses, including the need for training of highly qualified technicians and core losses (8, 24). Moreover, it has been criticized that TMA may not accurately represent histopathological characteristics of the whole-tissue section. Nonetheless, it has been shown that punching of multiple cores from different representative tumor regions reduces sampling error (15) and provides reliable results even for heterogeneous tumors $(25,26)$.

In conclusion, our results suggest that FISH is a robust technique and that it can be used for the determination of HER2 status in core biopsies. The high concordance rates between HER2 gene amplification status determined on whole-tissue and on random TMA sections (99.0\%) suggest that reliable results can be achieved even when tumor area is randomly chosen. Moreover, the observed agreement rates fulfill the ASCO/CAP recommendation of concordance greater than $95 \%$ for clearly amplified and non-amplified cases $(4,5)$. Furthermore, the high concordance rates between whole-tissue and diagnostic TMA sections justify the implementation of TMA for the determination of HER2 amplification on surgical specimens in the framework of quality control.

\section{Conflicts of Interests}

None to declare.

\section{Acknowledgements}

The Authors express special thanks to Drs. Anne Choquette, Michel Beauchemin, Mohamed Amin Hashem, Sophie Laberge, Mohib Morcos, Nathalie Mourad, Alexandre Odashiro, and Ion Popa. We are grateful to the personnel of the Service de Pathologie, especially to Céline Plourde, for their precious technical support.

DF received doctoral fellowships from the Fonds de recherche du Québec - Santé (FRQS) and the Laval University Cancer Research Center. CD is a recipient of the Canadian Breast Cancer Foundation-Canadian Cancer Society Capacity Development award (award \#703003) and the FRQS Research Scholar.

This study was supported by the Fondation des Hôpitaux EnfantJésus - St-Sacrement. Clinical specimens were provided by the Fondation du cancer du sein du Québec and the Banque de tissus et de données of the Réseau de recherche sur le cancer of the FRQS, which is affiliated with the Canadian Tumour Repository Network.

The Authors also acknowledge Hoffmann-La Roche Limited for its support.

\section{References}

1 Yarden $\mathrm{Y}$ and Sliwkowski MX: Untangling the ERBB signalling network. Nat Rev Mol Cell Biol 2(2): 127-137, 2001.

2 Soerjomataram I, Louwman MW, Ribot JG, Roukema JA and Coebergh JW: An overview of prognostic factors for long-term survivors of breast cancer. Breast Cancer Res Treat 107(3): 309330, 2008.

3 Esteva FJ, Yu D, Hung MC and Hortobagyi GN: Molecular predictors of response to trastuzumab and lapatinib in breast cancer. Nat Rev Clin Oncol 7(2): 98-107, 2010. 
4 Wolff AC, Hammond ME, Hicks DG, Dowsett M, McShane LM, Allison KH, Allred DC, Bartlett JM, Bilous M, Fitzgibbons P, Hanna W, Jenkins RB, Mangu PB, Paik S, Perez EA, Press MF, Spears PA, Vance GH, Viale G, Hayes DF, American Society of Clinical Oncology and College of American Pathologists: Recommendations for human epidermal growth factor receptor 2 testing in breast cancer: American Society of Clinical Oncology/College of American Pathologists clinical practice guideline update. J Clin Oncol 31(31): 3997-4013, 2013.

5 Wolff AC, Hammond ME, Schwartz JN, Hagerty KL, Allred DC, Cote RJ, Dowsett M, Fitzgibbons PL, Hanna WM, Langer A, McShane LM, Paik S, Pegram MD, Perez EA, Press MF, Rhodes A, Sturgeon C, Taube SE, Tubbs R, Vance GH, van de Vijver M, Wheeler TM, Hayes DF and American Society of Clinical Oncology/College of American P: American Society of Clinical Oncology and College of American Pathologists guideline recommendations for human epidermal growth factor receptor 2 testing in breast cancer. Arch Pathol Lab Med 131(1): 18-43, 2007.

6 Furrer D, Sanschagrin F, Jacob S and Diorio C: Advantages and disadvantages of technologies for HER2 testing in breast cancer specimens. Am J Clin Pathol 144(5): 686-703, 2015.

7 Ross JS: Point: Fluorescence in situ hybridization is the preferred approach over immunohistochemistry for determining HER2 status. Clin Chem 57(7): 980-982, 2011.

8 Camp RL, Charette LA and Rimm DL: Validation of tissue microarray technology in breast carcinoma. Lab Invest $80(12)$ : 1943-1949, 2000.

9 Gillett CE, Springall RJ, Barnes DM and Hanby AM: Multiple tissue core arrays in histopathology research: A validation study. J Pathol 192(4): 549-553, 2000.

10 Kononen J, Bubendorf L, Kallioniemi A, Barlund M, Schraml P, Leighton S, Torhorst J, Mihatsch MJ, Sauter G and Kallioniemi OP: Tissue microarrays for high-throughput molecular profiling of tumor specimens. Nat Med 4(7): 844-847, 1998.

11 Tubbs RR, Pettay JD, Swain E, Roche PC, Powell W, Hicks DG and Grogan T: Automation of manual components and image quantification of direct dual label fluorescence in situ hybridization (FISH) for HER2 gene amplification: A feasibility study. Appl Immunohistochem Mol Morphol 14(4): 436-440, 2006.

12 Gancberg D, Di Leo A, Rouas G, Jarvinen T, Verhest A, Isola J, Piccart MJ and Larsimont D: Reliability of the tissue microarray based FISH for evaluation of the HER 2 oncogene in breast carcinoma. J Clin Pathol 55(4): 315-317, 2002.

13 Graham AD, Faratian D, Rae F and Thomas JS: Tissue microarray technology in the routine assessment of HER2 status in invasive breast cancer: A prospective study of the use of immunohistochemistry and fluorescence in situ hybridization. Histopathology 52(7): 847-855, 2008.

14 O'Grady A, Flahavan CM, Kay EW, Barrett HL and Leader MB HER2 analysis in tissue microarrays of archival human breast cancer: Comparison of immunohistochemistry and fluorescence in situ hybridization. Appl Immunohistochem Mol Morphol 11(2): 177-182, 2003.
15 Zhang D, Salto-Tellez M, Putti TC, Do E and Koay ES: Reliability of tissue microarrays in detecting protein expression and gene amplification in breast cancer. Mod Pathol 16(1): 7984,2003

16 Fons G, Hasibuan SM, van der Velden $J$ and ten Kate FJ: Validation of tissue microarray technology in endometrioid cancer of the endometrium. J Clin Pathol 60(5): 500-503, 2007.

17 Hoos A, Urist MJ, Stojadinovic A, Mastorides S, Dudas ME, Leung DH, Kuo D, Brennan MF, Lewis JJ and Cordon-Cardo C: Validation of tissue microarrays for immunohistochemical profiling of cancer specimens using the example of human fibroblastic tumors. Am J Pathol 158(4): 1245-1251, 2001.

18 Buggi F, Folli S, Curcio A, Casadei-Giunchi D, Rocca A, Pietri E, Medri L and Serra L: Multicentric/multifocal breast cancer with a single histotype: Is the biological characterization of all individual foci justified? Ann Oncol 23(8): 2042-2046, 2012.

19 Choi Y, Kim EJ, Seol H, Lee HE, Jang MJ, Kim SM, Kim JH, Kim SW, Choe G and Park SY: The hormone receptor, human epidermal growth factor receptor 2, and molecular subtype status of individual tumor foci in multifocal/multicentric invasive ductal carcinoma of breast. Hum Pathol 43(1): 48-55, 2012.

20 Apple SK, Lowe AC, Rao PN, Shintaku IP and Moatamed NA: Comparison of fluorescent in situ hybridization HER-2/neu results on core needle biopsy and excisional biopsy in primary breast cancer. Mod Pathol 22(9): 1151-1159, 2009.

21 D'Alfonso T, Liu YF, Monni S, Rosen PP and Shin SJ: Accurately assessing HER-2/neu status in needle core biopsies of breast cancer patients in the era of neoadjuvant therapy: Emerging questions and considerations addressed. Am J Surg Pathol 34(4): 575-581, 2010.

22 Jourdan F, Sebbagh N, Comperat E, Mourra N, Flahault A, Olschwang S, Duval A, Hamelin R and Flejou JF: Tissue microarray technology: Validation in colorectal carcinoma and analysis of p53, hMLH1, and hMSH2 immunohistochemical expression. Virchows Arch 443(2): 115-121, 2003.

23 Khouja MH, Baekelandt M, Sarab A, Nesland JM and Holm R: Limitations of tissue microarrays compared with whole-tissue sections in survival analysis. Oncol Lett 1(5): 827-831, 2010.

24 Conway C, Dobson L, O'Grady A, Kay E, Costello S and O'Shea D: Virtual microscopy as an enabler of automated/ quantitative assessment of protein expression in TMAs. Histochem Cell Biol 130(3): 447-463, 2008.

25 Giltnane JM and Rimm DL: Technology insight: Identification of biomarkers with tissue microarray technology. Nat Clin Pract Oncol 1(2): 104-111, 2004.

26 Gomaa W, Ke Y, Fujii H and Helliwell T: Tissue microarray of head and neck squamous carcinoma: Validation of the methodology for the study of cutaneous fatty acid-binding protein, vascular endothelial growth factor, involucrin and $\mathrm{Ki}$ 67. Virchows Arch 447(4): 701-709, 2005.

Received July 4, 2016

Revised July 19, 2016

Accepted July 21, 2016 